Investigación Clínica:

\section{Reemplazo de aorta ascendente con paro circulatorio con hipotermia sistémica moderada y perfusión cerebral retrógrada}

\author{
Ricardo Zalaquett ${ }^{1 *}$, Katia González ${ }^{* *}$, Evelyn Borchert² ${ }^{2}$, verónica Sepúlveda ${ }^{2}$. \\ 1. Sección de Cirugía Cardiaca, Facultad de Medicina, Pontificia Universidad Católica de Chile. \\ 2. División de Anestesiología, Facultad de Medicina, Pontificia Universidad Católica de Chile. \\ ${ }^{*}$ Actualmente en Clínica Las Condes, Santiago Chile. \\ ${ }^{* * A c t u a l m e n t e ~ e n ~ C l i ́ n i c a ~ A l e m a n a, ~ S a n t i a g o ~ C h i l e . ~}$ \\ Financiamiento: Ninguno. \\ Conflicto de interés: Ninguno.
}

Antecedentes: El daño neurológico es una complicación devastadora de la cirugía con paro circulatorio del cayado aórtico y aorta ascendente. La perfusión anterógrada del encéfalo permite disminuir la incidencia de esta complicación, pero es un procedimiento engorroso que interfiere el campo quirúrgico. Para procedimientos más simples que requieran de paro circulatorio de menor duración, la Perfusión Cerebral Retrógrada (PCR) es una alternativa válida.

Objetivo: Evaluar nuestros resultados en la cirugía del reemplazo total de la aorta ascendente tubular con paro circulatorio con hipotermia sistémica moderada y PCR. Material y Método: Entre enero de 2015 y enero de 2020 se identificaron los pacientes en la Base de Datos del Servicio de Cirugía Cardiaca de nuestra institución, se revisaron los protocolos operatorios, registros de perfusión y epicrisis, para obtener datos demográficos, clínicos y quirúrgicos pertinentes. La supervivencia alejada se certificó a través del "Servicio Registro Civil e Identificación de Chile".

Resultados: En el periodo en estudio, 27 pacientes (21 hombres) tuvieron un reemplazo total de la aorta ascendente tubular con paro circulatorio con hipotermia mo- derada y PCR. Ocho pacientes tenían una cirugía previa; 7 de estos un reemplazo valvular aórtico. El 75\% de los otros 20 pacientes tenía una válvula aórtica bicúspide. El diámetro máximo de la aorta ascendente fue en promedio $53,7 \mathrm{~mm}$ (45 a 67), y fue reemplazada en el $52 \%$ de los casos con un tubo protésico de $34 \mathrm{~mm}$ (promedio:32,4 mm; margen:30 a $34 \mathrm{~mm}$ ). En 20 pacientes se efectuó un reemplazo valvular aórtico (15 con prótesis biológica). El tiempo promedio de circulación extracorpórea fue 174,6 min (97 a 243) y la temperatura sistémica mínima promedio fue $21^{\circ} \mathrm{C}$ ( 18 a 25). El tiempo promedio de paro circulatorio fue $22,3 \min (12$ a 40) y de PCR 13 min (6 a 27). No hubo mortalidad operatoria. La morbilidad más frecuente fue la fibrilación auricular (33\%). Una paciente presentó un episodio convulsivo aislado y otro fue reoperado por hemorragia postoperatoria. Una paciente falleció a los 48 meses de su operación.

Conclusión: El paro circulatorio con hipotermia sistémica moderada y PCR para la cirugía de reemplazo total de la aorta ascendente facilitó la operación, con baja mortalidad y morbilidad en este grupo de pacientes.

Palabras claves: Aneurisma aórtico; paro circulatorio; hipotermia; perfusión cerebral retrógrada. 


\section{Total Replacement of the Ascending Aorta with Moderate Systemic Hypothermic Circulatory Arrest and Retrograde Cerebral Perfusion}

Background. Neurological damage is a devastating complication of aortic arch and ascending aorta surgery with deep hypothermic circulatory arrest. Antegrade cerebral perfusion significantly decreases the incidence of this complication, but it is a cumbersome procedure that interfere the surgical field. For more simple procedures, requiring a shorter period of circulatory arrest, retrograde cerebral perfusion (RCP) would be a valid alternative.

Objective. To evaluate the results of total surgical replacement of the tubular ascending aorta with moderate hypothermic circulatory arrest and retrograde cerebral perfusion (RCP).

Methods. Patients operated between January 2015 and January 2020 were included.Demographic, clinical and surgical information was obtained from the operatives notes, perfusion registry and discharge reports. Long-term survival was certified by the "Chilean Civil and Identification Registry".

Results. 27 patients (21 men) underwent a total replacement of the tubular ascending aorta with circulatory arrest with moderate hypothermia and RCP. Eight patients had been previously operated on; 7 of them had a previous aortic valve replacement. Of the remaining 20 patients, $75 \%$ had a bicuspid aortic valve. Average maximum diameter of the ascending aorta was $53.7 \mathrm{~mm}(45-67)$. Average size of the ascending aorta replacement graft was $32.4 \mathrm{~mm}(30-34)$. In 20 patients a concomitant aortic valve replacement was performed (15 with a biological valve). Mean extracorporeal circulation time was $174.6 \min (97-243)$ and mean minimal systemic temperature was $21^{\circ} \mathrm{C}(18-25)$. Mean circulatory arrest time was $22.3 \mathrm{~min}(12-40)$ and mean RCP time was 13 min $(6-27)$, There was no operative mortality. Atrial fibrillation was the most frequent post-operative morbidity (33\%). One patient presented an isolated convulsive episode and another was re-operated due to postoperative hemorrhage. One patient died, 48 months after her operation.

Conclusion. Moderate hypothermic circulatory arrest with RCP simplifies total tubular ascending aorta replacement, with low mortality and morbidity. Keywords. Aortic aneurysm; circulatory arrest; hypothermia; retrograde cerebral perfusion. 


\section{Introducción:}

Si bien DeBakey y Cooley ${ }^{1}$ efectuaron la primera resección exitosa del arco aórtico a fines de los años 50, utilizando circulación extracorpórea con canulación femoral y perfusión cerebral selectiva a través del tronco innominado y la arteria carótida izquierda, en general la mortalidad y morbilidad fue muy elevada, en especial el daño neurológico permanente, lo que desincentivó a la mayoría de los cirujanos con este tipo de cirugía. En los años 70 Griepp y colaboradores ${ }^{2}$, en la Universidad de Stanford, introdujeron el "Paro Circulatorio con Hipotermia Sistémica Profunda” (PCHSP), entendiendo por tal una temperatura corporal entre $10^{\circ} \mathrm{C}$ y $18^{\circ} \mathrm{C}$. Con esto, se perseguían 2 objetivos principales: Minimizar el daño isquémico cerebral, al disminuir al máximo las demandas metabólicas del encéfalo, y simplificar la cirugía del arco aórtico y aorta ascendente distal, evitando el pinzamiento de la aorta ascendente. Esto último facilitaba la anastomosis aorto-protésica distal, al ofrecer un campo operatorio exangüe, libre de pinzas y de cánulas introducidas en los grandes troncos del cayado aórtico, a la vez que permitía efectuar esta anastomosis en forma "abierta", en la que ambas bocas anastomóticas eran circulares, y no una circular (prótesis) y otra elíptica (aorta). Además, prevenía un eventual daño tisular de la aorta ascendente, de particular importancia en casos de disección aórtica, a la vez que disminuía el riesgo de embolias de trombos o material aterosclerótico al encéfalo. Todo esto mantiene plena validez ${ }^{3}$.

Sin embargo, rápidamente se observó que la duración del paro circulatorio era un factor de riesgo de daño neurológico y de mortalidad operatoria. Los mismos cirujanos de Stanford ${ }^{4}$ observaron que cuando este se prolongaba por más de 25 minutos aumentaba la incidencia de daño neurológica transitorio. Svensson y Crawford ${ }^{5}$, en Baylor en un estudio en 656 pacientes, comunicaron un aumento significativo de daño neurológico permanente cuando el paro circulatorio se extendía por más de 45 minutos y de la mortalidad cuando este se prolongaba por más de 65 minutos. Así, en general, se estableció como límite "seguro" de PCHSP un tiempo de hasta 30 minutos.

Con el objeto de aumentar la protección cerebral durante el PCHSP, Ueda y colaboradores introdujeron en 1990 la "Perfusión Cerebral Retrógrada" (PCR), para perfundir el cerebro con sangre oxigenada y fría a través de la vena cava superior, lo que permitiría suministrar al encéfalo oxígeno y nutrientes metabólicos durante el PCHSP, a la vez que facilitaría un enfriamiento más homogéneo de este y permitiría la remoción de eventuales embolias gaseosas o particuladas y de microagregados celulares desde los grandes vasos, así como la remoción de metabolitos, disminuyendo la acidosis producida por la isquemia cerebral ${ }^{6}$.

Durante los años 90 numerosos grupos quirúrgicos comunicaron experiencias exitosas con la PCR como complemento del $\mathrm{PCHSP}^{7,8}$. Por nuestra parte, nosotros comunicamos nuestra propia experiencia en 1995, la que habíamos iniciado ya en 1993 en pacientes con disección aórtica tipo A de Stanford ${ }^{9}$. Sin embargo, simultáneamente se fue generando cierta incertidumbre respecto a la real efectividad de la PCR, a pesar de las sólidas bases experimentales y clínicas en la que se sustentaba, en cuánto a perfundir efectivamente el encéfalo, así como una cierta preocupación en cuanto a un riesgo de mayor incidencia de edema cerebral Ello agregado a la ya existente preocupación, al menos teórica, en cuanto a la perfusión sistémica retrógrada que significaría el retorno arterial desde la máquina de circulación extracorpórea a través de la arteria femoral común, en especial en casos de aterosclerosis periférica extensa y de disección aórtica $7,8,10-13$. Para estas situaciones, a mediados de los años 90 se introdujo la canulación de la arteria axilar, en especial de la derecha ${ }^{14}$. Rápidamente se observó que esto facilitaba la perfusión anterógrada selectiva del cerebro durante el PCHSP, a través de la simple oclusión del tronco innominado. Como muchos grupos, nosotros iniciamos nuestra experiencia con la canulación de la arteria axilar en 1998, comunicando nuestros resultados en 2003, con lo que paulatinamente la PCR como complemento del PCHSP se fue haciendo muy esporádica en nuestra práctica, a la vez que la hipotermia dejo de ser en muchos casos "profunda" para ser "moderada", por sobre los $18^{\circ} \mathrm{C}^{15}$.

Sin embargo, la disección y posterior canulación de la arteria axilar, en muchas, ocasiones resulta laboriosa e incluso una operación en sí misma, por lo que paulatinamente comenzamos a limitar su uso para los casos aterosclerosis periférica extensa o disección aórtica y para los casos de cirugía compleja del arco aórtico que requirieran periodos de paro circulatorio muy prolongados. $\mathrm{Se}$ volvió así a la canulación femoral y a la PCR como complemento del paro circulatorio, ahora con hipotermia sistémica moderada, para aquellos casos de resección completa de la aorta ascendente, o "hemiarco", pero que no requieran periodos de paro circulatorios prolongados ${ }^{16}$.

\section{Material y método:}

El estudio se efectuó entre el 1 de enero de 2015 y el 
31 de enero de 2020 e incluyó a todos los pacientes con aneurisma de la aorta ascendente tubular, operados exclusivamente por el primer autor, con hipotermia sistémica moderada y PCR. Los pacientes fueron identificados en la Base de Datos de la Sección de Cirugía Cardiovascular y de los Registro de Perfusión Cardiovascular, de la Facultad de Medicina de la Pontificia Universidad Católica de Chile. Se revisaron los protocolos operatorios, registros de perfusión y epicrisis. La supervivencia alejada se certificó a través del "Servicio de Registro Civil e Identificación de Chile".

Se incluyeron pacientes en quienes se efectuó un reemplazo de aorta ascendente con paro circulatorio con hipotermia moderada y PCR. Se tabularon variables demográficas, incidencia del procedimiento en relación a otras técnicas, comorbilidad, cirugía previa, diámetro del aneurisma de aorta ascendente, patología valvular aórtica, tiempo de circulación extracorpórea y oclusión aórtica (tiempo de isquemia miocárdica), temperatura sistémica mínima, tiempo de paro circulatorio y tiempo de PCR, diámetro del tubo protésico aórtico y tipo de prótesis valvular aórtica, tiempo de ventilación mecánica (día de extubación), tiempo de estadía hospitalaria, evolución postoperatoria intrahospitalaria y supervivencia alejada. Los resultados se presentan como promedio y margen para las variables numéricas y en porcentaje para las variables categóricas. $\mathrm{Al}$ ser este un estudio observacional y descriptivo no comparativo, no se realizó un análisis estadístico propiamente tal.

Técnica quirúrgica. Simultáneamente o luego de la esternotomía, se diseca la arteria femoral común, identificando certeramente la arteria femoral profunda (en esta experiencia, en todos los casos, correspondió a la femoral común derecha). Luego de la pericardiotomía y heparinizado el paciente, se procede a la canulación directa de esta arteria a través de una arteriotomía transversa, con una cánula Bio-Medicus 21 French o una Cánula EOPA 20 French (ambas Medtronic) y a continuación, a la canulación venosa con una cánula única de 3 estadios Edwards Lifesciences 29 French, introducida a través de la orejuela derecha hacia la vena cava inferior. A continuación se cánula el seno coronario, por vía transauricular derecha, con una cánula de seno coronario Edwards Lifescience 24 French, para infusión de solución cardioplégica por vía retrógrada. Se entra en circulación extracorpórea con hipotermia sistémica moderada y a continuación se coloca un catéter en el tercio medio de la aorta ascendente para infusión de solución cardioplégica por vía anterógrada. Se pinza la aorta ascendente y se procede a la detención de la actividad electromecánica del corazón con solución cardioplégica cristaloide St. Thomas, infundida por vía anterógrada y retrógrada. Durante el resto del procedimiento el corazón es protegido con solución cardioplégica infundida exclusivamente en el seno coronario cada 15 a 20 minutos. Hipotermia tópica también es utilizada. Detenido el corazón, se coloca un vent auriculo-ventricular izquierdo introducido a través de la vena pulmonar superior derecha.

En estas condiciones, se procede a resecar la aorta ascendente proximal, desde aproximadamente 5 a $10 \mathrm{~mm}$ del plano de los ostia coronarios, y luego a efectuar un reemplazo valvular aórtico, si es el caso. A continuación se procede a canular la vena cava superior, muy próxima a su llegada a la aurícula derecha, con una cánula en ángulo recto Edwards Lifesciences 20 French, alrededor de la cual se coloca una cinta vascular elástica azul en doble lazada, para impedir la regurgitación de sangre a la aurícula derecha. Se controla meticulosamente la hemostasia retro aórtica y se procede a la anastomosis aorto-protésica proximal del tubo protésico de Dacron seleccionado, con una sutura continua en un plano, con Prolene 4-0 con aguja $\mathrm{C} 1$.

Terminada esta anastomosis proximal, y alcanzada la temperatura sistémica programada en la nasofaringe, se coloca al paciente en posición de Trendelemburg, se detiene completamente la circulación extracorpórea, con exanguinación parcial del paciente hacia el reservorio del circuito de circulación extracorpórea, y se procede a resecar la aorta ascendente distal, hasta aproximadamente 5 a $10 \mathrm{~mm}$ del origen del tronco innominado, extendiendo la resección hacia la curvatura menor del arco aórtico ("Hemiarco"), para proceder a la anastomosis aorto-protésica distal, siempre con una sutura continua de Prolene 4-0 con aguja $\mathrm{C} 1$ en un plano, comprendiendo en esta al remanente de aorta ascendente. Avanzada la parte posterior de esta anastomosis se inicia la PCR, tensando la cinta elástica alrededor de la cava superior. Terminada esta anastomosis distal, se reinicia la circulación extracorpórea con recalentamiento sistémico del paciente, se detiene la PCR y se libera la oclusión de la cava superior. El aire es removido de las cavidades cardiacas izquierdas y del cayado aórtico y sus grandes vasos a través de la misma línea de sutura aorto-protésica distal, previo a ser anudada, y de aspiración continua del vent auriculo-ventricular izquierdo. 
Técnica de perfusión cerebral retrógrada. Ya en paro circulatorio, pinzadas las líneas de perfusión arterial sistémica y de drenaje venoso y ocluida la vena cava superior alrededor de la cánula 20 French, introducida en esta proximalmente, con una cinta vascular elástica, se inicia la PCR con sangre oxigenada, a la temperatura en la que se inició el paro circulatorio, con un flujo de 8 a $10 \mathrm{ml} /$ $\mathrm{Kg} /$ minuto, manteniendo la presión del circuito de circulación extracorpórea, medida en el extremo arterial de este, bajo $40 \mathrm{mmHg}$. La determinación de la presión en la vena cava superior o yugular interna es más variable, dependiendo de dónde este la punta del catéter o si este quedo atrapado por el torniquete elástico, pero debe mantenerse entre 15 a $25 \mathrm{mmHg}$ para disminuir la incidencia de edema cerebral. Con el mismo objetivo, preferimos mantener el flujo de la PCR bajo $500 \mathrm{~mL} / \mathrm{min}$.

\section{Resultados:}

Pacientes. Se identificaron 27 pacientes portadores de un Aneurisma de Aorta Ascendente que tuvieron un reemplazo de ésta con paro circulatorio sistémico con hipotermia moderada y PCR. Veintiún pacientes $(78 \%)$ eran hombres. La edad promedio fue 66,8 años, con un margen de 56 a 86 años.

En este periodo (1 de enero 2015 a 31 de enero de 2020) se efectuaron 44 cirugías de aorta ascendente por el primer autor. Por tanto, estos 27 pacientes representaron el $61 \%$ de este total. 20 pacientes $(74 \%)$ se operaron en los 2 últimos años del periodo.

Comorbilidad. Las principales comorbilidades fueron la hipertensión arterial en 16 casos (59\%) y la diabetes mellitus en $5(18,5 \%)$.

Cirugía previa. Ocho pacientes $(29,6 \%)$ habían tenido una cirugía cardiovascular previa. Seis casos correspondieron a un reemplazo valvular aórtico con prótesis mecánica, de los cuales 3 tenían una disfunción protésica trombótica ( 2 crónica y 1 aguda), siendo esta la indicación quirúrgica primaria; en los otros 3 , la indicación quirúrgica primaria fue el aneurisma de la aorta ascendente y la prótesis fue dejada in situ. Un paciente de 86 años tenía un reemplazo valvular aórtico con prótesis biológica efectuado 18 años antes, que se encontraba normofuncionante y también fue dejada in situ. El paciente restante presentaba un bypass coronario efectuado 10 años atrás. (Tabla 1)

Valvulopatía aórtica. Descontados los 7 pacientes con
TABLA 1. Cirugía de aorta ascendente enero 2015 - enero 2020.

\begin{tabular}{l|c|c|}
\hline & $N^{\circ}$ & $\%$ \\
\hline Total Cirugías & 44 & 100 \\
\hline Cirugías HSM y PCR & 27 & 61 \\
Hipertensión* $^{*}$ & 16 & 59 \\
Diabetes* $^{*}$ & 5 & 18,5 \\
Cirugía Previa* $^{*}$ & 8 & 29,6 \\
\hline HSM: Hipotermia Sistémica Moderada. & PCR: Perfusión Cerebral Retrógrada
\end{tabular}

cirugía valvular aórtica previa, 15 de estos 20 pacientes restantes $(75 \%)$ tenían una válvula aórtica bicúspide.

Del total de los pacientes, 10 tenían una estenosis aórtica, 7 una insuficiencia aórtica y 3 una disfunción protésica. De los pacientes restantes, 3 tenían una válvula aórtica competente ( 2 tricúspide) y cuatro una prótesis aórtica normofuncionante.

Aneurisma aórtico. Todos los pacientes tenían un aneurisma de la aorta ascendente con diámetro máximo promedio a nivel mesoaórtico de 53,7 mm, con un margen de 45 a 67 mm. Ningún caso correspondió a una disección aórtica tipo A de Stanford.

Cirugía aorta ascendente. En todos los pacientes se efectuó un reemplazo de la aorta ascendente tubular con un tubo protésico de Dacron, con un diámetro promedio de 32,4 mm y un margen de 30 a $34 \mathrm{~mm}$; en el $52 \%$ de los casos se utilizó un tubo protésico de $34 \mathrm{~mm}$.

Cirugía valvular aórtica. En 15 pacientes se efectuó un reemplazo valvular aórtico con una prótesis biológica y en 5 con una prótesis mecánica. (Como se señaló en "Valvulopatía aórtica", 3 pacientes tenían una válvula aórtica competente y 4 una prótesis valvular aórtica normofuncionante).

Cirugía asociada. En 2 pacientes se efectuó una revascularización miocárdica (1 con arteria mamaria y otro con vena safena) y en otro paciente un parche con pericardio bovino de un pseudoaneurisma ventricular izquierdo de pared inferior (el paciente había presentado un infarto inferior tratado con angioplastia 3 meses antes).

Circulación extracorpórea. El tiempo promedio de circulación extracorpórea fue 174,6 minutos (margen: 97 a $243 \mathrm{~min}$ ) y el tiempo de pinzamiento aórtico 110 minutos (margen: 60 a $155 \mathrm{~min}$ ). La temperatura sistémica mínima fue en promedio $21^{\circ} \mathrm{C}$, con un margen de $18^{\circ} \mathrm{C}$ a 
Tabla 2. Parámetros de CEC y Paro Circulatorio en 27 pacientes con cirugía de Reemplazo de aorta ascendente con HSM y PCR.

\begin{tabular}{l|c|c|}
\hline & Promedio & Margen \\
\cline { 2 - 3 } CEC (min) & 174,6 & $97-243$ \\
Clamp Aórtico (min) & 110 & $60-155$ \\
Temperatura Mínima $\left({ }^{\circ} \mathrm{C}\right)$ & 21 & $18-25$ \\
Paro Circulatorio $(\mathrm{min})$ & 22,3 & $12-40$ \\
\hline PCR (min) & 13 & $6-27$ \\
\hline HSM: Hipotermia Sistémica Moderada. PCR: Perfusión Cerebral Retrógrada. \\
CEC: Circulación Extracorpórea.
\end{tabular}

$25^{\circ} \mathrm{C}$. (En los 2 primeros pacientes de esta serie la temperatura sistémica mínima fue de $18^{\circ} \mathrm{C}$; en los pacientes restantes fue de $20^{\circ} \mathrm{C}$ o más). (Tabla 2 ).

Paro circulatorio. El tiempo promedio de paro circulatorio total fue 22,3 minutos, con un margen de 12 a 40 minutos. El tiempo de PCR fue en promedio 13 minutos, con un margen de 6 a 27 minutos. (Tabla 2).

Estadía hospitalaria y ventilación mecánica. La estadía hospitalaria promedio fue 10,3 días, con un margen de 6 a 19 días. El 85\% de los pacientes fueron desconectados de ventilación mecánica el primer día de postoperatorio. El tiempo promedio de ventilación mecánica fue de 1,3 días, con un margen de 1 a 6 días.

Mortalidad operatoria. No hubo mortalidad hospitalaria ni postoperatoria a 30 días.

Morbilidad perioperatoria. La Tabla 3 resume la mor-

Tabla 3. Morbilidad post operatoria en 27 pacientes con reemplazo de aorta Ascendente con HSM y PCR.

\begin{tabular}{l|c|c|} 
& $N^{\circ}$ & $\%$ \\
\hline Fibrilación Auricular & 9 & 33 \\
Marcapaso & 3 & 11 \\
Derrame Pericárdico & 3 & 11 \\
Absceso Inguinal & 1 & 3,7 \\
Neumonia AAS & 1 & 3,7 \\
Insuficiencia Cardiaca FEP & 1 & 3,7 \\
Neumotórax & 1 & 3,7 \\
Sangrado Post Operatorio & 1 & 3,7 \\
Episodio Convulsivo & 1 & 3,7 \\
\hline HSM: Hipotermia Sistémica Moderada. AAS: Asociado a Atención de Salud. \\
FEP. Fracción de Eyección Preservada. \\
PCR: Perfusión Cerebral Retrógrada.
\end{tabular}

bilidad perioperatoria. Un tercio de los pacientes (9 casos) presentó fibrilación auricular en el postoperatorio, en la mayoría de los casos de fácil control con Amiodarona en infusión. Tres pacientes requirieron de un implante de marcapaso bicameral definitivo (2 por bloqueo aurículo-ventricular completo y otro por una enfermedad del nódulo sinusal preoperatoria) y otros 3 presentaron un derrame pericárdico significativo, el que sin embargo no requirió drenaje. Un paciente fue reoperado por hemorragia postoperatoria el mismo día de su operación, sin encontrarse un sitio de sangrado activo.

Un paciente requirió drenaje de un absceso inguinal en relación a la canulación femoral. Una paciente fue re hospitalizada por insuficiencia cardiaca con fracción de eyección preservada y otro paciente por neumonía.

Una paciente de 66 años, con un deterioro cognitivo leve, presentó en el post operatorio inmediato un episodio convulsivo que se trató con Lorazepam IV. El electroencefalograma mostró solo actividad lenta generalizada y el scanner cerebral fue normal (neurología consideró el episodio más probablemente relacionado al uso de Ácido Tranexámico). La paciente fue desconectada de ventilación mecánica al $2^{\circ}$ día de post operatorio. Otra paciente de 66 años presentó un neumotórax izquierdo asociado a desadaptación a la ventilación mecánica que requirió de sedación por 6 días, pero sin signos neurológicos de focalización.

Sobrevivencia alejada. El seguimiento se cerró el 30 de junio de 2020 y se completó en el 100\% de los casos, con un promedio de 23 meses y un margen de 6 a 57 meses. Una paciente falleció a los 48 meses de su operación y próxima a cumplir 80 años, por un accidente vascular encefálico. En esta paciente se había efectuado un reemplazo valvular aórtico con una prótesis mecánica de St. Jude HP, número 19.

\section{Discusión:}

La cirugía de la aorta ascendente y del cayado aórtico están entre los procedimientos de mayor complejidad de la cirugía cardiovascular, siendo técnicamente muy demandante y con un riesgo neurológico inherente de consideración. Los procesos patológicos principales son la disección aórtica Tipo A de Stanford y los aneurismas, degenerativos o ateroscleróticos, de la aorta ascendente y/o del cayado aórtico.

En los años 70's, Griepp y colaboradores ${ }^{2}$, en Stanford, introdujeron el PCHSP para la cirugía del cayado aórtico, lo cual simplificó importantemente el procedimiento 
quirúrgico propiamente tal. El paro circulatorio permite un campo operatorio exangüe, libre de pinzas o cánulas que entorpezcan el procedimiento, y la hipotermia minimiza la injuria isquémica al encéfalo, al disminuir sus demandas metabólicas de oxígeno y glucosa. Rápidamente, el PCHSP se extendió a aneurismas de la aorta ascendente que requirieran su resección completa, lo que algunos han dado en llamar "hemiarco", puesto que para este fin la resección se extiende en un par de centímetros hacia la curvatura menor del cayado aórtico, y a la disección aórtica Tipo A de Stanford. En prácticamente todas estas situaciones el retorno arterial desde la máquina de circulación extracorpórea se hacía a través de la arteria femoral común ${ }^{3}$.

Como señalamos ya en la introducción, rápidamente se hizo evidente que la prolongación del paro circulatorio era un factor determinante de daño neurológico y de mortalidad operatoria, a pesar de la "protección" que ofrecía la hipotermia sistémica profunda ${ }^{4,5}$. En 1990, Ueda y colaboradores 6 introducen la PCR continua, como complemento de la hipotermia, para reducir la incidencia de daño neurológico y extender el periodo "seguro" de paro circulatorio, permitiendo además la remoción de aire o material particulado desde el cayado aórtico y sus grandes vasos, que pudiesen ser embolizados al cerebro. Si bien la PCR había sido reportada ya en 1980 por Mills y Ochsner ${ }^{17}$ para tratar la embolia aérea accidental durante la circulación extracorpórea, la comunicación de Ueda tuvo gran aceptación y prácticamente todos los grupos interesados en la cirugía aórtica comenzaron a comunicar resultados exitosos con la PCR como complemento del PCHSP; entre ellos, nosotros, comunicando, en 1995, nuestros resultados en 15 pacientes con disección aórtica tipo A de Stanford ${ }^{7-9}$. Pero, como ya también señalamos en la introducción, a fines de los años 90 se fue generando una cierta incertidumbre respecto a la efectividad de la PCR y una preocupación en cuanto a los riesgos de la perfusión sistémica retrógrada a través de la arteria femoral común ${ }^{10-13}$, lo que coincidió con la reintroducción, por el grupo de la Cleveland Clinic $^{14}$, de la canulación de la arteria axilar, procedimiento que por nuestra parte iniciamos a fines de los años $90^{15}$, Comenzamos a utilizar la PCR en forma cada vez más esporádica, a la vez que la hipotermia se fue haciendo cada vez más moderada, puesto que esta permitía la fácil perfusión selectiva del encéfalo.

Sin embargo, la canulación axilar es un procedimiento en muchos casos engorroso y la alternativa de canular la arteria innominada siempre nos ha producido aprehen- sión, a pesar de los reportes auspiciosos al respecto ${ }^{18}$. Es por esto que paulatinamente, para pacientes que requieren un reemplazo de toda la aorta ascendente "tubular", entendiendo como tal desde la unión sinotubular hasta el cayado aórtico, pero en los que es posible asumir periodos de paro circulatorio más limitados, volvimos a utilizar paulatinamente la PCR, como complemento de la hipotermia sistémica, ahora moderada, y canulación femoral. La canulación axilar la reservamos para casos de disección aórtica y para la cirugía del arco aórtico, como recientemente comunicamos con el uso de la prótesis Thoraflex ${ }^{19}$.

Así, en los últimos 5 años, 27 pacientes (78\% hombres) con aneurisma de la aorta ascendente degenerativo, en la mayoría de los casos asociado o secundario a una valvulopatía aórtica bicúspide, fueron operados con paro circulatorio con hipotermia sistémica moderada y PCR. Estos pacientes representaron el $61 \%$ del total de pacientes (44) operados por aneurisma de aorta ascendente, en el periodo, por el primer autor. El resto de los pacientes correspondieron a cirugía limitada a la raíz aórtica, en los que se efectuó algún procedimiento tipo "Bentall”, o a pacientes con aneurismas muy circunscritos a la porción media de la aorta ascendente, en la que esta fue reemplazada parcialmente, solo con pinzamiento de la aorta distal, sin paro circulatorio. Esto último, en la práctica actual del autor es cada vez más infrecuente, favoreciendo el reemplazo total, en la mayoría de los casos, y porque la anastomosis aorto-protésica distal en esas condiciones es más engorrosa e imprecisa, ya que el pinzamiento aórtico hace que el remanente de aorta asuma una configuración elíptica mientras el tubo protésico mantiene su configuración circular, lo que se traduce en una línea de sutura más imperfecta y menos hemostática.

Si bien el periodo en estudio fue de 5 años, la gran mayoría de los pacientes (74\%) se operaron en los últimos 2 años, en particular en el año 2019. Esto ha sido el resultado de la progresiva apreciación por el primer autor de la simplicidad del procedimiento, así como su efectividad y baja morbilidad y mortalidad, pero también fuertemente influenciado por las guías clínicas para la aortopatía relacionada a la válvula aórtica bicúspide de la American Association for Thoracic Surgery, publicadas en $2018^{20}$. Estas recomiendan "considerar" el reemplazo de la aorta ascendente cuando esta alcanza los $50 \mathrm{~mm}$ e "indicarla" cuando alcanza los $55 \mathrm{~mm}$. Cuando la indicación quirúrgica "primaria" es el recambio de la válvula aórtica, las guías recomiendan reemplazar la aorta concomitantemente cuando esta alcanza un diámetro de $45 \mathrm{~mm}$. El 
diámetro promedio de la aorta en esta experiencia fue $53,7 \mathrm{~mm}$, con un margen de 45 a $67 \mathrm{~mm}$.

La técnica de PCR es básicamente la misma que la descrita en nuestra publicación de $1995^{9}$, salvo que se ha privilegiado últimamente, por nuestros perfusionistas, medir la presión del circuito de circulación extracorpórea por sobre la presión en la vena cava superior, si bien en la mayoría de los casos se determinan ambas. Es fundamental mantener estas presiones, así como el flujo de la PCR, dentro de los límites sugeridos (ver Técnica de PCR) para disminuir la incidencia de edema cerebral. Por otra parte, en el último tiempo hemos comenzado paulatinamente monitorizar la oxigenación cerebral en forma no invasiva, usando la "espectroscopía del infrarrojo cercano", conocido como NIRS, por su sigla en inglés. Este es un método simple, cuya interpretación no requiere entrenamiento especial y se correlaciona bien con el Doppler transcraneal $^{16,21}$.

El tiempo promedio de paro circulatorio fue de 22,3 minutos (12 a $40 \mathrm{~min}$.), lo que si bien estaría dentro de los límites originalmente recomendados, esto era en condiciones de $\mathrm{PCHSP}^{4,5}$. En esta experiencia, la temperatura sistémica mínima fue en promedio $21^{\circ} \mathrm{C}$, con un margen de $18^{\circ} \mathrm{C}$, para los 2 primeros pacientes, a $25^{\circ} \mathrm{C}$, para los últimos (estos 2 primeros pacientes se incluyeron para demostrar la evolución del autor en cuanto a la magnitud de la hipotermia, si bien el consenso actual es considerar hipotermia moderada entre $20,1^{\circ} \mathrm{C}$ a $28^{\circ} \mathrm{C} 22$ ). Es nuestra opinión que, si bien la hipotermia es fundamental para la protección encefálica, también lo es para la protección de los otros órganos corporales, por lo que a pesar de que el encéfalo se pueda perfundir selectivamente, tanto en forma retrógrada como anterógrada, es necesario mantener cierto grado de hipotermia durante el paro circulatorio aun cuando ello implique un mayor tiempo de circulación extracorpórea.

Como ha sido ya desde hace bastante tiempo en nuestra práctica, construimos las anastomosis aorto-protésicas con una sola línea de sutura corrida de Prolene 4-0, con aguja C1. Nunca utilizamos bandas de teflón-felt y muy excepcionalmente utilizamos algún tipo de pegamento, incluidas las disecciones. Consideramos que las bandas facilitan los desgarros tisulares e impiden precisar bien los sitios de sangrado, así como que ningún pegamento supera a una anastomosis construida meticulosa y cuidadosamente, con una sutura fina y una aguja completamente atraumática, reforzada solo en los sitios que correspondan.

Es destacable, a pesar de lo limitado de la serie, que no haya habido mortalidad operatoria. Igualmente, la morbilidad operatoria fue baja, siendo la más frecuente la fibrilación auricular, en general de fácil control. En lo que respecta a la morbilidad típicamente asociada a la cirugía aórtica, solo un paciente requirió ser reoperado por hemorragia postoperatoria, a pesar de que casi un tercio de estos correspondieron a reoperaciones, y en ellos no se encontró un sitio de sangrado activo, También es destacable que solo una paciente presentó un episodio convulsivo, el que se consideró más probablemente secundario al uso profiláctico de Ácido Tranexámico. También es destacable que ningún paciente haya lpresentado un daño neurológico permanente (la Base de Datos de la STS muestra que el riesgo de muerte del reemplazo aislado de la aorta ascendente es 3,4\% y el de accidente cerebro-vascular 3,2\% 20 ).

Finalmente, si bien el seguimiento fue limitado, en promedio 23 meses, solo una paciente falleció durante este periodo, a los 4 años de su operación y próxima a cumplir 80 años, por un accidente vascular encefálico.

En conclusión, y a pesar de ser esta una experiencia observacional y descriptiva, no comparativa y limitada, es posible sostener que el paro circulatorio sistémico con hipotermia moderada y PCR, simplifica técnicamente el reemplazo completo de la aorta ascendente "tubular" por aneurisma degenerativo y ofrece buenos resultados operatorios, con baja mortalidad y morbilidad, en especial una baja incidencia de sangrado post operatorio y complicaciones neurológicas. 


\section{Referencias}

1- COOLEY DA, MAHAFFEY DF, DeBAKEY ME. Total excision of the aortic arch aneurysm. Surg Gynecol Obstet 1955;101:667-72.

2- GRIEPP RB, STINSON EB, HOLLINGSWORTH JF, et al. Prosthetic replacement of the aortic arch. J Thorac Cardiovasc Surg 1975:70:1051-63.

3- ERGIN MA, GRIEPP EB, LANSMAN SL, et al. Hypothermic circulatory arrest and other methods of cerebral protection during operations on the thoracic aorta. J Card Surg 1994;9:525-37.

4- ERGIN MA, GALLA JD, LANSMAN SL, et al. Hypothermic circulatory arrest in operations on the thoracic aorta. Determinants of operative mortality and neurologic outcome. J Thorac Cardiovasc Surg 1994;107:788-97.

5- SVENSSON LG, CRAWFORD ES, HESS KR, et al. Deep hypothermia with circulatory arrest. Determinants of stroke and early mortality in 656 patients. J Thorac Cardiovasc Surg 1993;106:19-28.

6- UEDA Y, MIKI S, KUSUHARA K, et al. Surgical treatment of aneurysm or dissection involving the ascending aorta and aortic arch, utilizing circulatory arrest and retrograde cerebral perfusión. J Cardiovasc Surg 1990;31:553-8.

7- SAFI HJ, LETSOU GV, ILIOPOULOS DC et al. Impact of retrograde cerebral perfusión on ascending aortic and arch aneurysm repair. Ann Thorac Surg 1997;63:1601-7.

8- COSELLI JS, LeMAIRE SA. Experience with retrograde cerebral perfusión during proximal aortic surgery in 290 patients. J Card Surg 1997;12:322-5.

9- ZALAQUETT R, IRARRAZAVAL MJ, MORAN S et al. Retrograde cerebral perfusión during circulatory arrest with profound hypothermia. Rev Méd Chile 1995;123:1489-98.

10- USUI A, OOHARA K, LIU T, et al. Comparative experimental study between retrograde cerebral perfusion and circulatory arrest. J Thorac Cardiovasc Surg 1994;107:1228-36.

11- YASUURA K, OGAWA Y, OKAMOTO H, et al. Clinical application of total body retrograde perfusión to operation for aortic dissection. Ann Thorac Surg 1992;53:655-8.
12- NOJIMA T, MAGARA T, NAKAJIMA Y, et al. Optimal perfusión pressure for experimental retrograde cerebral perfusión. J Card Surg 1994;9:548-59.

13- WAREING TH, DAVILA ROMAN VG, BARZILAI B et al. Management of the severely atherosclerotic ascending aorta during cardiac operation. J Thorac Cardiovasc Surg 1992;103:453-62.

14- SABIK JF, LYTLE BW, McCARTHY PM et al. Axillary artery: an alternative site of arterial cannulation for patients with extensive aortic and peripheral vascular disease. J Thorac Cardiovasc Surg 1995; 109:855-91.

15- ZALAQUETT R, BAHAMONDES JC, MERTENS R, et al. Cannulation of axillary artery for extracorporeal circulation. Rev Méd Chile 2003;131:390-6.

16- TANAKA A, ESTRERA AL. Simple retrograde cerebral perfusión is as good as complex antegrade cerebral perfusión for hemiarch replacement. J Vis Surg 2018;4:50-7.

17- MILLS NL, OCHSNER JL. Massive air embolism during cardiopulmonary bypass. Causes, prevention and management. J Thorac Cardiovasc Surg 1980;80:708-17.

18- SEGUEL E, STOCKINS A, GONZALEZ R, et al. Canulación de la arteria innominada para conexión a circulación extracorpórea en cirugía de la aorta. Rev Chil Cirug 2015;67:88-92.

19- ZALAQUETT R, REYES R, GONZALEZ P. Reemplazo de arco aórtico y aorta descendente proximal por aneurisma o disección aórtica con prótesis Thoraflex. Rev Chil Cardiol 2018;37:18-25.

20- BORGER MA, FEDAK PWM, STEPHENS EH, et al. The American Association for Thoracic Surgery consensus guidelines on bicúspide aortic valve-related aortopathy: Full online-only versión. J Thorac Cardiovasc Surg 2018;156e41-74.

21- CHAN MJ, CHUNG T, GLASSFORD NJ et al. Near-infrared spectroscopy in adult cardiac surgery patients: a systematic review and meta-analysis. J Cardiothorac Vasc Anesth 2017;31:1155-65.

22- YAN TD, BANNON PG, BAVARIA J, et al. Consensus on hypothermia in aortic arch surgery. Ann Cardiothorac Surg 2013;2:163-168. 